\title{
Immunohistochemical localization of a specificileal peptide in the pig
}

\author{
A. Borgstrom, M. Wider, W. Marks, R. Lloyd, G. Herman, and A. Vinik \\ The Departments of Surgery and Interna1 Medicine, Division of Endocrinology and Metabolism and Department of \\ Pathology, The University of Michigan, Ann Arbor, Michigan 48109, USA, and the Department of Medical Research Sinai \\ Hospital of Detroit, Michigan 48235, USA
}

Received November 11, 1985 / Accepted June 12, 1986

\begin{abstract}
Summary. The tissue distribution of a polypeptide purified from pig ileal mucosa tentatively called porcine ileal polypeptide (PIP) and known to have potent acid secretagogue activity has been studied with immunohistochemical methods together with extraction of different tissues followed by radioimmunoassay for PIP content. Histochemically the peptide is found in superficial epithelial cells in the mucosa of the distal $20 \%$ of the small intestine and to some extent in the mucosa of the urinary tract. There is no staining of goblet cells or crypt cells. The staining in the urinary tract mucosa is due to antigenic peptides with Mr identical to PIP. While the presence of PIP in the ileum is compatible with a function as an enterooxyntin, it is not possible at present to explain the physiologic role of PIP entirely as a hormone regulating acid secretion in light of the immunohistochemical distribution.
\end{abstract}

\section{Introduction}

Several specific peptides have been found in the gut either in nerves or in special endocrine cells dispersed among the epithelial cells in the deeper crypt layers of the mucosa (Pearse et al. 1977; Said 1984). Many of these peptides do not as yet have established physiologic functions. Both humans and animals have been found to secrete putative hormones which inhibit (enterochalone) or enhance (enterooxyntin) gastric acid secretion. In experiments with the isolated perfused canine jejunum it has been demonstrated that a potent gastric acid secretogogue is released into the medium (Walker et al. 1983). This agent acts both through a $\mathrm{Ca}^{++}$dependent and histamine $\mathrm{H}_{2}$ receptor pathway (Strodel et al. 1985).

We recently reported on the isolation and purification of a 13,000 dalton (Mr) peptide from pig ileal mucosa tentatively named porcine ileal polypeptide (PIP) (Wider et al. 1984). The isolated peptide stimulates oxyntic cell hydroxyl ion production in sections of guinea pig gastric fundus in vitro in concentrations in the range of $10^{-15}-10^{-9} \mathrm{M}$ and is thus a potent enterooxyntin. The purpose of this work

Supported in part by a grant from the NIH AM-27077 and the Sinai Hospital General Research Fund

Offprint requests should be sent to: Aaron I. Vinik, M.D., University of Michigan Medical Center, Room B2922 Taubman Health Care Center, Box 046, 1405 E. Ann Street, Ann Arbor, MI 48109, USA was to study the distribution of PIP in different tissues with special attention to the gastrointestinal tract in an effort to clarity its biologic function.

\section{Material and methods}

Specimens. Tissue samples from salivary glands, esophagus, stomach, duodenum, upper and lower jejunum, upper, mid and lower ileum, proximal, mid and distal colon were taken from a 3-month old pig $(16 \mathrm{~kg})$ under pentobarbital anesthesia. Samples from heart, lung, diaphragm, liver, gallbladder, sciatic nerve, vagal nerve, skeletal muscle, pancreas, spleen, adrenal gland, kidney, ureter, urinary bladder and skin were also harvested. All samples were collected in phosphate-buffered, $10 \%$ formalin, and the paraffin embedded tissue sections were used for immunohistochemical staining.

Immunohistochemistry. Endogenous peroxidase was inhibited by incubation of the slides with equal parts of absolute methanol and $3 \% \mathrm{H}_{2} \mathrm{O}_{2}$ for $10 \mathrm{~min}$. This was followed by a $10-\mathrm{min}$ incubation with normal goat serum diluted 1:20 to reduce nonspecific background staining. All dilutions were made with a phosphate buffer $(0.05 \mathrm{~mol} / \mathrm{l})$ containing $\mathrm{NaCl}(0.15 \mathrm{~mol} / \mathrm{l})$, bovine serum albumen $(40 \mathrm{~g} / \mathrm{l})$ and normal goat serum $(1 \% \mathrm{v}: \mathrm{v})$ at $\mathrm{pH}$ 7.4. A polyclonal monospecific rabbit anti-PIP serum (APS 53) was used. Antibody specificity was checked by immunoelectrophoresis in agarose and showed only a single precipitation line against crude pig ileal extract. The tissue sections were incubated for $2-3 \mathrm{~h}$ at room temperature with this antiserum diluted 1:5,000-1:40,000. A biotinylated goat anti-rabbit IgG antiserum and an Avidin peroxidase complex, both obtained from Vector (Vectastain) were used according to the manufacturer's instructions. The substrate, 3-3'-diaminobenzidine tetrahydrochloride $(0.4 \mathrm{~g} / 1$, in $0.05 \mathrm{~mol} / 1$ phosphate buffer, containing $\mathrm{NaCl}, 0.15 \mathrm{~mol} / \mathrm{l}$ and $\mathrm{H}_{2} \mathrm{O}_{2} 0.05 \%$ at pH 7.4) from (Sigma Chemical Company St. Louis Mo) was used for development of the color complex of the immune precipitate. The slides were then counterstained with hematoxylin (Gill No 3 Sigma Chemical Co.)

Specificity of staining was determined by immune neutralization using fragment $\mathrm{B}$, the largest fragment of PIP obtained following cyanogen bromide treatment of the native peptide (Wider et al. 1984). The antiserum, diluted 1:10,000, was incubated with fragment $B$ in three different concentrations 5,50 , and $500 \mathrm{ng} / \mathrm{ml}$ for $48 \mathrm{~h}$ at $+4 \mathrm{C}$ before application to the sections.

Tissue extractions. The distribution of PIP in the gastrointestinal tract was further evaluated by tissue extraction followed by radioimmunoassay. The entire GI tract was obtained from two pigs at the local abbatoir at the time of slaughter. The mucosa was scraped from the fundus, corpus, and the antrum of the stomach, duodenum and from $30 \mathrm{~cm}$ sections of small intestine taken every $60 \mathrm{~cm}$ from duodenum to the ileocecal valve. Samples of mucosa 
were taken from the proximal, mid and distal colon as well. The mucosa was homogenized in $20 \mathrm{ml}$ of $0.05 \mathrm{M} \mathrm{NH}_{4} \mathrm{HCO}_{3}$ containing benzamidine hydrochloride $0.001 \mathrm{~mol} / 1$ and EDTA, $0.01 \mathrm{~mol} / 1$ $\mathrm{pH} 8.6$ in a Waring blender, followed by 20 strokes in a Dounce homogenizer. The homogenate was centrifuged at $10,000 \mathrm{rpm}$ for $30 \mathrm{~min}$ at $+4^{\circ} \mathrm{C}$ and the $\mathrm{pH}$ of the supernatant was adjusted to 4.5 with $\mathrm{HCl}$. A precipitate formed and was removed by centrifugation at $10,000 \mathrm{rpm}$ for $30 \mathrm{~min}$ at $+4^{\circ} \mathrm{C}$. The $\mathrm{pH}$ of the supernatant was adjusted to 8.6 with $\mathrm{NH}_{4} \mathrm{OH}$ and aliquots of each sample were diluted $1: 1,000$ in Veronal buffer $\mathrm{pH} 8.6$. The samples were stored at $-20^{\circ} \mathrm{C}$ until assayed.

The urinary bladders from two pigs were frozen on solid $\mathrm{CO}_{2}$, pulverized in a Waring blender and homogenized in the $\mathrm{NH}_{4} \mathrm{HCO}_{3}$ buffer described above. The homogenate was then centrifuged at $10,000 \mathrm{rpm}$ for $30 \mathrm{~min}$ at $+4^{\circ} \mathrm{C}$ and the supernatant was stored at $-20^{\circ} \mathrm{C}$ until further assayed.

Gel filtration experiments. Gel filtration of extracts of ileal and bladder mucosa were performed on a Sephadex G50 Fine $(1,5 \times 90 \mathrm{~cm})$ eluted with a $\mathrm{NH}_{4} \mathrm{HCO}_{3}$ buffer $(0.05 \mathrm{~mol} / 1)$ containing benzamidine hydrochloride $0.001 \mathrm{~mol} / 1$ at $+4^{\circ} \mathrm{C}$. The column was standardized before and after each run with Blue dextran, 125I-PIP and ribonuclease. An internal standard of 125I-PIP was run with each sample.

Radioimmunoassay. All samples from the extraction procedures and columns were assayed for immunoreactive PIP (IRPIP) using a radioimmunoassay as described previously (Wider et al. 1986). Essentially the assay is incubated in a barbital buffer, $\mathrm{pH} 8.6$ using a second antibody for separation of bound and free labeled PIP. The assay has a detection limit of $0.5 \mathrm{ng} / \mathrm{ml}$ and a sensitivity of $0.1 \mathrm{ng} / \mathrm{ml}$. The intra-assay variation coefficient for samples in the sensitive range was $5 \%$ and all samples from single experiments were assayed simultaneously.

\section{Results}

\section{Immunohistochemistry}

In the gastrointestinal tract immunoreactive PIP (IRPIP) was mainly found immunohistochemically in the distal small intestine. In the proximal ileum IRPIP was confined within scattered single cells in the superficial mucosa (Fig. 1). In the distal ileum all superficial enterocytes except for goblet cells stained for IRPIP (Fig. 2). No cells in the deeper layers of the musosa or in the crypts were stained.

No IRPIP was found in heart, lung, diaphragm, liver, gallbladder, sciatic nerve, vagal nerve, skeletal muscle, pancreas, spleen, adrenal gland, kidney or skin using these antibody concentrations. In the urinary tract however IRPIP was seen in the mucosa of the ureter and the urinary bladder. In the bladder the staining was seen throughout the mucosa (Fig. 3) except for the most superficial cuticule. In the ureter only occasional cells scattered in the deeper layers of the mucosa stained for IRPIP (Fig. 4).
While the ileal mucosa stained intensly with antibody dilutions of $1: 40,000-1: 20,000$, these antibody concentrations gave no or, barely visible staining of the mucosa of the urinary tract. For intense staining in the urinary tract higher antibody concentrations of $1: 10,000-1: 15,000$ had to be used. This could be done without appearance of any visible background staining.

Preincubating the antibody diluted $1: 10,000$, with fragment B of PIP in a concentration of $5 \mathrm{ng} / \mathrm{ml}$ or more, completely blocked staining of the urinary tract mucosa. Addition of 5 and $50 \mathrm{ng} / \mathrm{ml}$ of fragment B decreased staining of the ileal mucosa while $500 \mathrm{ng} / \mathrm{ml}$ was needed to completely block all staining in the ileal mucosa.

\section{Tissue extractions}

The distribution of extractable IRPIP in the GI tract is shown in Fig. 5 together with the extractable amounts of IRPIP from whole urinary bladder tissue and skeletal muscle. The highest concentration of PIP was found in the ileal mucosa with negligable amounts in the proximal small intestine, large bowel and urinary bladder. No IRPIP was detected in gastric mucosa or skeletal muscle.

Gel filtration of extracts from urinary bladder and ileal mucosa demonstrated a single peak of IRPIP from both extracts eluting coincident with the 125I-PIP run as internal standard (Fig. 6).

\section{Discussion}

In this study we have shown that PIP immunoreactivity is uniquely distributed in the mucosa of the distal small intestine and to some extent in the mucosa of the urinary tract. The higher concentration of antibody needed for staining of IRPIP in the bladder mucosa may be due to crossreaction between two antigenically similar proteins, to the presence of a smaller amount of PIP in the urinary tract mucosa or technical differences in the immunohistochemical studies in the two types of tissues. That the differences in relate to concentrations within the tissues is favoured by the extraction data showing low concentrations of IRPIP in the urinary bladder and by the gel filtration studies showing immunoreactive peptides of identical elution volumes in ileal and bladder mucosa.

A cyanogen bromide generated fragment "B" was used for the immune neutralization studies to insure that blocking was due to PIP alone. This fragment contained the immunoreactive portion of the PIP molecule. It would be expected that any contaminating peptides in the isolated PIP preparation would not yield a fragment identical to PIP. Fragment B has a Mr only slightly smaller than PIP

Fig. 1. Immunohistochemical staining for porcine ileal polypeptide in proximal ileum. Scattered immunoreactive epithelial cells in the superficial mucosa are stained dark brown

Fig. 2. Immunohistochemical staining for porcine ileal polypeptide in distal ileum. Shows staining of all superficial enterocytes except for the goblet cells

Fig. 3. Immunohistochemical staining for porcine ileal polypeptide in the urinary bladder. Shows staining of mucosal cells throughout the mucosa except for the most superficial cuticule

Fig. 4. Immunohistochemical staining for porcine ileal polypeptide in the ureter. Shows staining of scattered cells in the deeper parts of the mucosa 

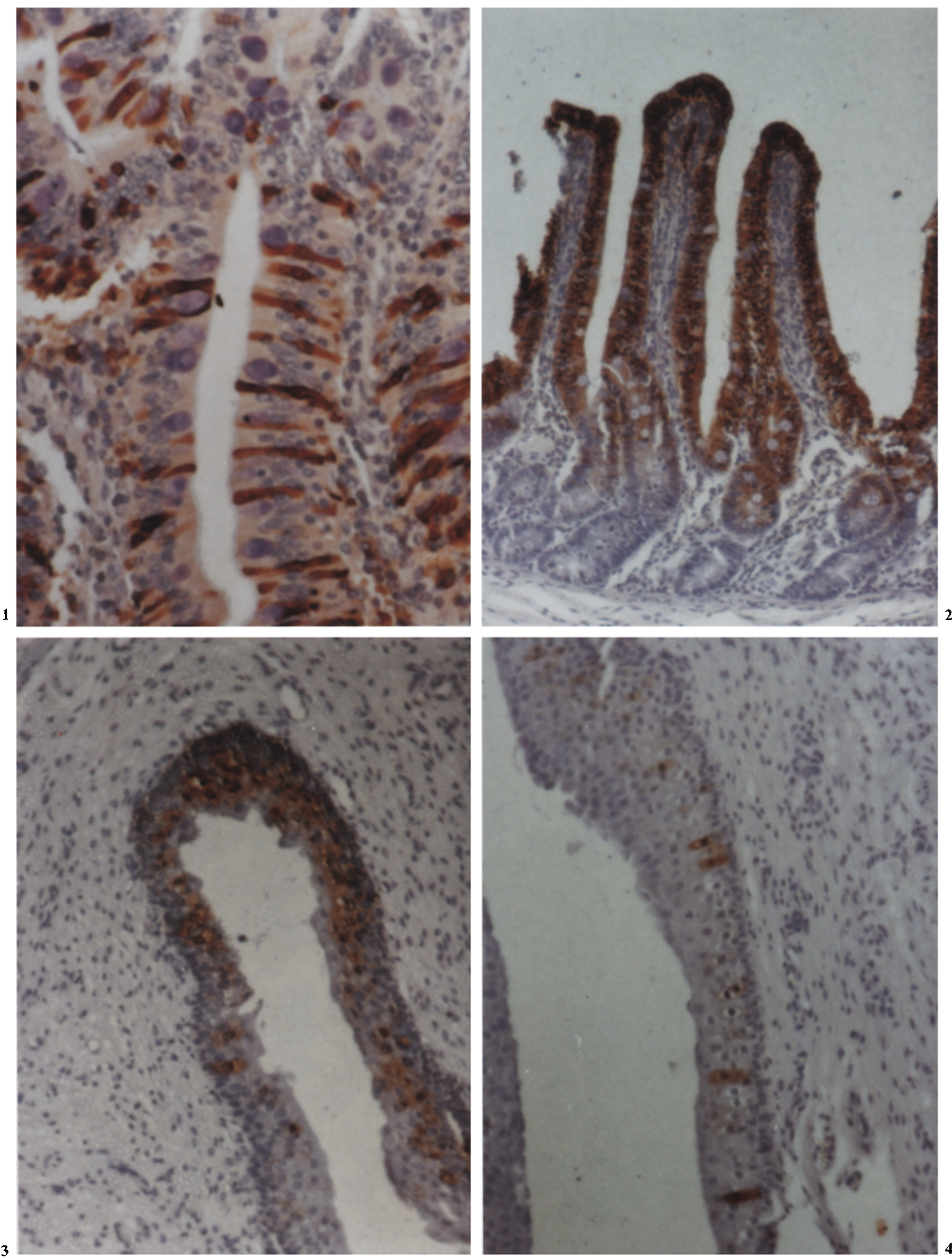


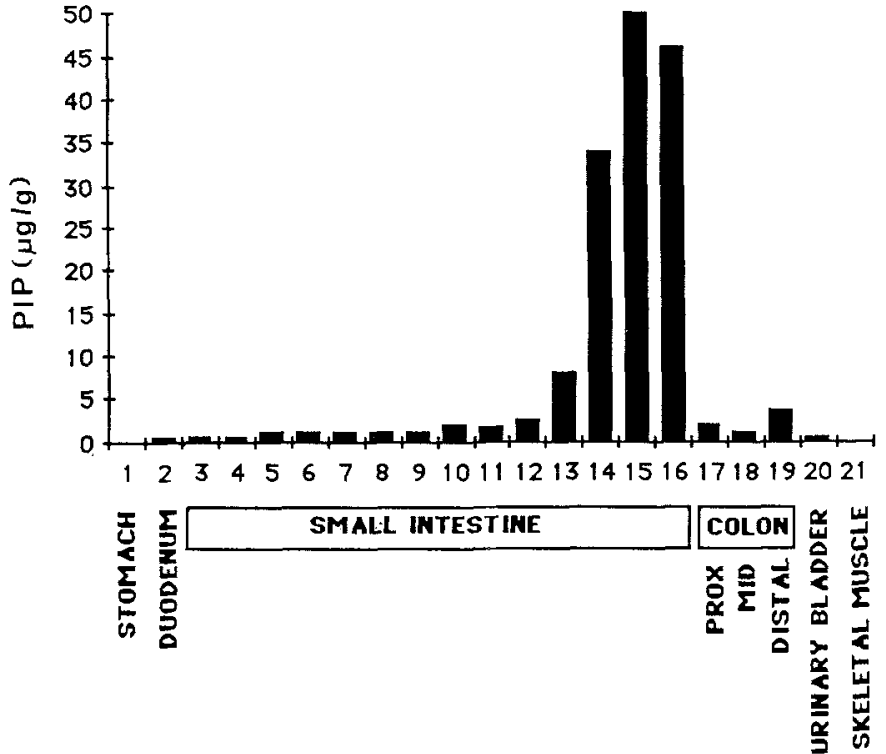

Fig. 5. Concentrations of immunoreactive PIP (IR-PIP) in various tissues expressed as $\mu \mathrm{g} / \mathrm{g}$ wet weight. Numbers indicate serial sections of ileal mucosa progressing distally from duodenum towards the colon

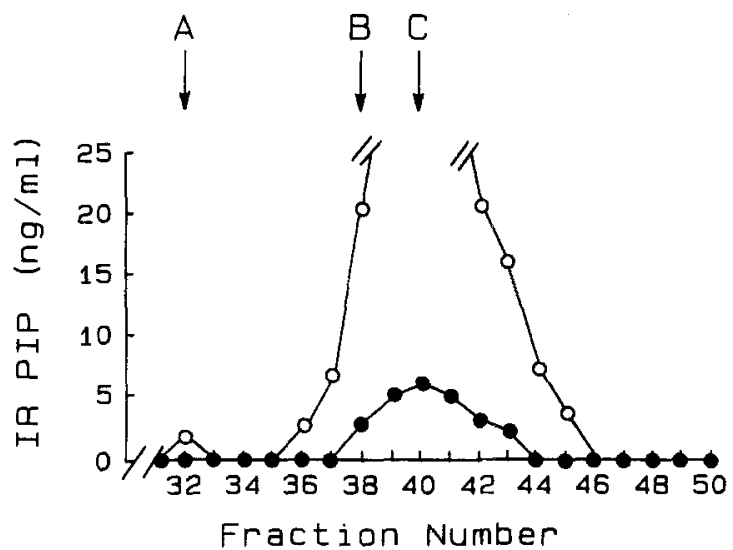

Fig. 6. Molecular sieve chromatography on Sephadex G 50 of IRPIP in extract from porcine ileal mucosa (open circles) and extract from urinary bladder (closed circles). $A=$ elution volume for blue dextran (void volume), $B=$ elution volume for Ribonuclease $A$ (MW 13,600) and $C=$ elution volume for 125I-PIP used as internal standard

and was indeed capable of neutralizing staining in both ileum and bladder.

PIP is thus mainly localized to the distal $20 \%$ of the small intestine with trace amounts observed in the urinary tract mucosa. The peptide has been identified in the circulation (Wider and Duhaime 1985a) and causes potent stimulation of gastric acid secretion, both in vitro and in vivo (Wider et al. 1984; Wider et al. 1986). This activity suggests an endocrine function of PIP, however, the superficial and especially the distal diffuse localization in ileum contrasts significantly with the localization of other gastrointestinal peptide hormones reported so far. Gut endocrine cells in the small intestine are more scattered among the epithelial lining of the intestinal crypts and to some extent also the basal parts of the villi (Pearse et al. 1977; El-Salhy et al. 1983; Buffa et al. 1978, 1979; Cristina et al. 1978; Lehy et al. 1980; Solcia et al. 1980).
The relationship between the different pools of PIP in ileal mucosa, bladder mucosa and plasma can only be speculated upon. The bulk of PIP in the body is evidently localized to the ileal mucosa. The majority of the plasma PIP is thus probably derived from this pool. The presence of small amounts of PIP in the urinary tract mucosa is puzzling. This is however not the only example of two distinct tissue types containing the same immunospecific protein (Heitz et al. 1978) but may reflect a general function of PIP in for example mucosal protection or mucosal absorption. It should however be noted that PIP is absent in the mucous cells of the intestinal mucosa.

The results in this report are difficult to interpret in light of the biologic activity studies. It seems unlikely that the stimulatory effect on parietal cell function of this peptide shown earlier in vivo and in vitro should be due to contaminating peptides since PIP is active at very low concentrations (10-15-10-9 mol/l). It is possible that PIP functions in the transport of a nutrient or of bile acids and that it provides a feedback signal to regulate gastric acidity as well. Itoh et al. (1979) have demonstrated that the peak acidity of the duodenum is reached at $8-12 \mathrm{~h}$ postprandially and drops to neutrality after $16 \mathrm{~h}$. This time interval corresponds to the time interval after eating when the terminal small intestine receives and eliminates chyme. Thus PIP derived from the ileum could function as an enterooxyntin a humoral factor derived from the ileum which has gastric acid secretory properties (Orlloff et al. 1980; Vagne 1980). The role of the peptide as an enterooxyntin requires further elucidation.

Regardless of the biological function of PIP the clinical implications of a specific ileal peptide are many. An assay for the corresponding human ileal peptide would be of interest in different small bowel diseases and for assesment of small bowel integrity and function.

\section{References}

Buffa R, Capella C, Fontana P, Usellini L, Solcia E (1978) Types of endocrine cells in the human colon and rectum. Cell Tissue Res 192:227-240

Buffa R, Grivelli O, Fiocca R, Fontana P, Solcia, E (1979) Complement-mediated unspecific binding of immunoglobulins to some endocrine cells. Histochemistry 63:15-21

Cristina M, Lehy T, Zeiloun P, Dufougeray F (1978) Fine structural classification and comparative distribution of endocrine cells in normal human large intestine. Gastroenterology 75:20-28

El-Salhy M, Grimelius L, Wilander E, Ryberg B, Terenius L, Lundberg JM, Tatemoto K (1983) Immunocytochemical identification of polypeptide YY (PYY) cells in the human gastrointestinal tract. Histochemistry 77:15-23

Heitz P, Kasper M, et al (1978) Immunohistochemical localization of urogastrone to human duodenal and submandibular glands. Gut 19:408-413

Itoh Z, Honda R, Takeuchi S, Aizawa I, Takahashi I, Mori K (1979) Postprandial changes in plasma secretin concentrations, pancreatic secretion and intraduodenal $\mathrm{pH}$ in the dog. In Miyoshi A (ed) Gut peptides. Elsevier North Holland Press, Amsterdam New York, pp 66-72

Lehy T, Peranzi G. Cristina ML (1980) Correlating immunocytochemical and electron microscopic studies. Identification of entero (glucagon)-, somatostatin- and pancreatic polypeptide-like containing cells in the human colon. Histochemistry 71:67-80

Orloff MJ, Hyde P, Kosta L, Guillemin C, Bell R Jr (1980) Intestinal phase hormoe that stimulates gastric acid secretion. In: 
Glass GBJ (ed) Gastrointestinal hormones. Raven Press, New York, pp 877-898

Pearse AGE, Polak JM, Bloom S (1977) Progress in gastroenterology. The newer gut hormones. Gastroenterology 72:746-761

Said SI (1984) Isolation, localization, and characterization of gastrointestinal peptides. Clin Biochem 17:65-67

Soleia E, Polak JM, Larsson LI (1981) Update en Lausanne classification of endocrine cells. In: Bloom SR, Polak JM (eds) Gut hormones, 2nd edn. Churchill Livingstone, Edinburgh, pp 96100

Strodel WE, Walker WA, Vinik BS, Heldsinger A, Eckhauser FE, Vinik AI (1985) Preliminary characterization of the mechanisms of action of entero-oxyntin (EO) on guinea pig oxyntic cell. Endocrinology 117:376-381
Vagne M (1980) Entero-Oxyntin. In: Glass GBJ (ed) Gastrointestinal hormones. Raven Press, New York, pp 877-898

Walker WA, Strodel WE, Eckhasuer FE, Vinik AI (1983) Enterooxyntin release from isolated perfused canine jejunum. J Surg Res 34:486-492

Wider MD, Vinik AI, Heldsinger A (1984) Isolation and parital characterization of an enterooxyntin from porcine ileum. Endocrinology 115:1484-1491

Wider DM, Duhaime PMQ (1985a) Chromatographic and electrophoretic characterization of immunoreactive porcine ileal polypeptide in plasma. Endocrinology 116 (Suppl): A656

Wider MD, Duhaime PMO, Weisman RL (1985b) Chemical characterization of circulating porcine ileal polypeptide in plasma from normal adult pigs. Endocrinology 118:1546-1550 